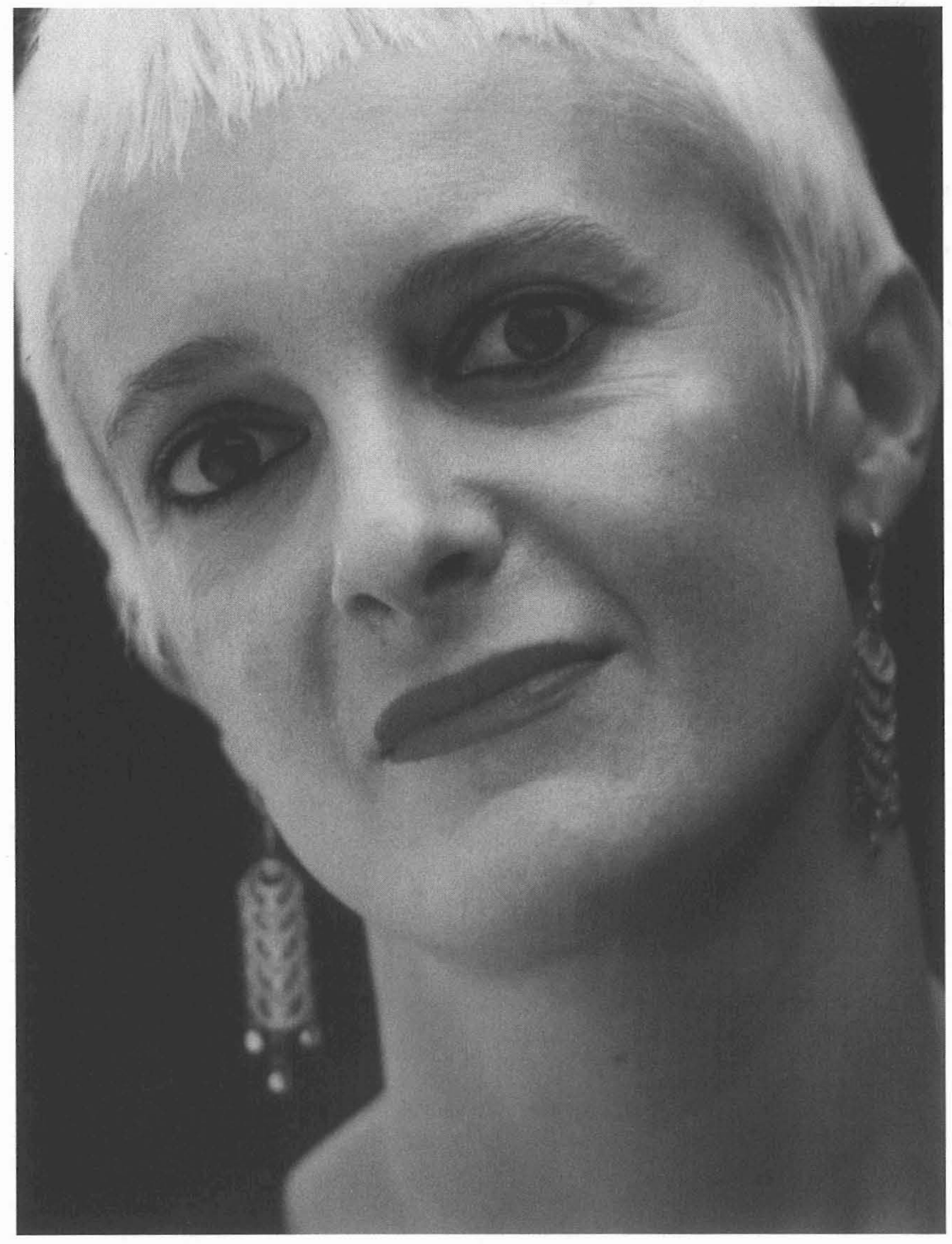

Chantal Danjou

58 LittéRéalité 


\section{Chantal Danjou}

Après de longues années parisiennes, Chantal Danjou vit et travaille désormais dans un petit village du Var. Docteur ès lettres, elle est professeur de français une dizaine d'années tout en menant une activité de critique et d'animation d'ateliers d'écriture. Par ailleurs, elle a dirigé La Roue Traversière, association qui, pendant douze ans, a tenté de mieux faire connaître les poètes contemporains d'expression française.

\section{Publications}

Recueils de poèmes : La Cendrifêre, chez l'auteur, 1980; Mythe de Migrale, Ed. St Germain des Prés, 1985; Le Livre de la Soif, Ed. L'Harmattan, 1993; Lieux / Dits, Ed. Ass. Clapas, coll. Franche Lippée, 1994; Les Consonnes de Sel, Ed. L'Harmattan, 1995; Muse au beau visage penché, Ed. Encres Vives, 1996; Terres Bleues, Ed. L'Harmattan, 1998; Eloge d'une absence verte, Ed. Encres Vives, 2002. Essai : Damier de silence et parole, essai et entretiens avec Jean-Claude Villain, Ed. L'Harmattan 2001. 


\section{T \\ O

"Nous avons, dans nos pièces de séjour, ce renfoncement qu'on appelle le "toko no ma", que nous ornons d'une peinture, d'un arrangement floral, mais la fonction essentielle de cette peinture, ou de ces fleurs, n'est pas décorative en soi, car il s'agit plutôt d'ajouter à l'ombre une dimension dans le sens de la profondeur. " - in Eloge de l'ombre - de Junichirô Tanizaki. 


\section{U]}

ne branche d'amandier en fleurs. Une odeur de miel et de laine humide. Peu à peu on perçoit distinctement les deux parfums. L'un agréable; le second trop fort et âcre.

L'ombre de la branche sur le mur blanc dessine un bref paysage. Une ligne de crêtes au-dessus des nuages. Ajoute-t-elle à l'opacité, à l'imaginaire? Les pétales vont si légers qu'ils ne sont plus que vent.

Bols en raku. Noirs en apparence. Placés devant la lumière, les couleurs montent. Petits bourgeons à éclore. Y a -t-il quelque chose de plus vain, de plus beau que ce couple buvant son thé matinal?

Un pétale est tombé dans le bol. La vie se resserre. Quel chemin mène à l'arbre? Celui du jardin plus secret où s'enfoncer en ôtant tous ses bijoux. Plus que nus dans un bain de fleurs qui recouvre les corps du jaune des fruits cueillis.

Des fumées lèvent. Dire de mémoire l'existence en contrebas d'un jardinet planté de citronniers. Les parfums créent le lieu réparateur. Même s'il ramène toujours à l'obscur.

Et ce rien, cette dense légèreté du pétale, l'habiter. Que reste-t-il dans le feu de la transparence? Peut-être une imperceptible rougeur au bord de l'invisible.

Des reflets. Une vallée. Des fleurs mais aucune feuilles. L’ombre d'une main. Le blanc se retire plus loin encore. Comme si le mur reculait. Quelle clarté pour résoudre l'obscur?

Que reste-t-il du monde? Cet espace fugitif. Entre flotter et se flétrir. Les mirages, les corps dansants, les nuages, les crêtes, les brumes. Un univers de conte. Un à un les pétales se détachent. Et le silence vient, accompagné d'élytres, de coassements, de gazouillis.

Tout est noir, mais... Ne pas ignorer dans cette certitude que plus rien ne bouge les fleurs à l'assaut de l'ombre. Impossible de ne pas sentir l'arbre remuer. Avant de mourir. Avant de se défaire de chair, de fleurs, de gouttes d'eau. Un lent mystère. Cette présence d'amandier dans l'inconnu. 